\title{
Happy Birthday! 85th Birthday of Edward R. Adlard
}

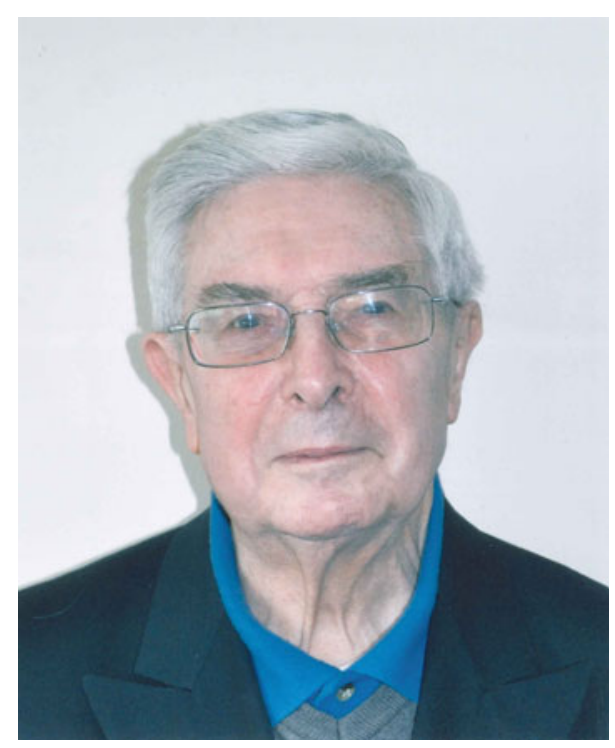

On 5 December 2012, Ted Adlard, Editor of Chromatographia, will celebrate his 85th birthday.

In the name of the editors, publisher and readers of Chromatographia we thank Ted for his tireless commitment to Chromatographia and congratulate him on his special day and wish him all the best for the future.

A tribute to Ted was published on the occasion of his 70th birthday in Chromatographia (1997) 46:578-579. doi:10.1007/BF02490515

\section{Steffen Pauly}

Executive Editor Chemistry, Springer

Petra Russkamp

Editorial Office Chromatographia, Springer 